\title{
Clinicopathological evaluation of focal reactive lesions of the Gingiva
}

SADJ September 2021, Vol. 76 No. 8 p465 - p470

C Karuma ${ }^{1}$, S Ngwenya ${ }^{2}$, S Shangase ${ }^{3}$

\section{ABSTRACT}

\section{Introduction}

Focal reactive gingival lesions are elicited by chronic irritation primarily due to dental plaque, calculus, overhanging dental restorations and ill-fitting dental prosthesis. Persistent irritation of the gingiva can lead to tissue injury and trigger inflammation leading to proliferation of endothelial cells, multi-nucleated giant cells, fibroblasts and tissue mineralisation.

\section{Aims}

The aim and objectives of the study were to determine the relative frequency and distribution of focal reactive gingival lesions according to sex, age, and anatomical site in patients who presented at the Witwatersrand Oral Health Centre.

\section{Design}

Retrospective cross-sectional study

\section{Methods}

Convenience sampling of patient records from the years 2011 to 2017 were analysed from the Department of Oral Pathology and the Department of Oral Medicine and Periodontology at the Witwatersrand Oral Health Centre. Sociodemographic variables and clinical features were evaluated.

\section{Author affiliations:}

1. Cliff Mirirai Karuma: BDS, BMedScHons (Applied Anatomy) $M S c$ (Dentistry), MScDent candidate: Department of Oral Pathology, School of Oral Health Sciences, Faculty of Health Sciences, University of the Witwatersrand, Johannesburg. ORCID ID: 0000-0003-4803-5985

2. Sizakele Pride Ngwenya: BSc, BDS, MDent (Oral Pathology) Head: Department of Oral Pathology, School of Oral Health Sciences, Faculty of Health Sciences, University of the Witwatersrand, Johannesburg.

ORCID ID: 0000-0002-9397-5178

3. Sindisiwe Shangase: BDS, MDent Head of Department, Department of Oral Medicine and Periodontology, School of Oral Health Sciences, Faculty of Health Sciences, University of the Witwatersrand, Johannesburg, South Africa.

ORCID Number: 0000-0003-0234-8089

Corresponding author:

Dr Sizakele Ngwenya: Sizakele.Ngwenya@wits.ac.za

\section{Author contributions:}

1. Cliff Mirirai Karuma: Data collection, analysis and interpretation first draft, revision, final write-up - 40\%

2. Sizakele Pride Ngwenya: Conceptualisation and design, data analysis and interpretation, first draft, revision, final write-up and approval 30\%

3. Sindisiwe Shangase: Conceptualisation and design, data analysis and interpretation, first draft, revision, final write-up and approval - $30 \%$

\section{Results}

Female patients accounted for $70.8 \%(n=172)$ of all focal reactive gingival lesions, with the majority of the lesions having occurred in the maxilla (56.4\%; $n=137)$. The age of patients ranged from 3 months to 88 years.

\section{Conclusion}

Contrary to findings in other studies, the peripheral ossifying fibroma was the most common focal reactive gingival lesion, after analysing 243 cases.

\section{Keywords}

Focal reactive gingival lesions, pyogenic granuloma, lobular capillary haemangioma. Peripheral ossifying fibroma, focal fibrous hyperplasia and peripheral giant cell granuloma.

\section{Nomenclature \\ FRGL : Focal reactive gingival lesions \\ LCH : Lobular capillary haemangioma \\ FFH : Focal fibrous hyperplasia \\ POF : Peripheral ossifying fibroma \\ PGCG : Peripheral giant cell granuloma \\ Rrb : Rank biserial correlation coefficient \\ DMF : Decayed, Missing and Filled}

\section{INTRODUCTION}

Focal reactive gingival lesions (FRGL) are gingival enlargements elicited by chronic irritation primarily due to over-hanging dental restorations, ill-fitting dental prostheses, plaque and calculus ${ }^{1}$. The gingiva bears the brunt of this chronic irritation and thus is the most common intra-oral site for these lesions ${ }^{2}$. Persistent irritation of the gingiva can lead to tissue injury and trigger inflammation leading to proliferation of endothelial cells, multi-nucleated giant cells, fibroblasts and tissue mineralisation ${ }^{3}$. The proliferation can eventually lead to a localised hyperplasia and an exuberant gingival mass ${ }^{4}$.

Even though FRGL have similar aetiological factors, the various lesions have characteristic histopathological features, and are considered by most authors as separate distinct lesions ${ }^{5}$. FRGL are generally classified into peripheral ossifying fibroma (POF), lobular capillary haemangima $(\mathrm{LCH})$, peripheral giant cell granuloma (PGCG) and focal fibrous hyperplasia $(\mathrm{FFH})^{6}$. Some authors have postulated that these pathological entities represent one lesion at various histological developmental stages ${ }^{7}$. They argue that a LCH may develop into a POF or FFH with time through further collagen build up and maturation ${ }^{8}$. However, if this hypothesis is true, a definite age grouping for the different histological entities should be apparent. 


\begin{tabular}{|c|c|c|c|c|c|}
\hline Variable & LCH $(n=80)$ & POF $(n=86)$ & FFH $(n=69)$ & PGCG $(n=8)$ & Total \\
\hline \multicolumn{6}{|l|}{ Gender } \\
\hline Male & 57 & 62 & 48 & 5 & 172 \\
\hline Female & 23 & 24 & 21 & 3 & 71 \\
\hline \multicolumn{6}{|l|}{ Age (years) } \\
\hline Range & $10-88$ & $0-72$ & 7-75 & $13-56$ & $0-88$ \\
\hline Mean & 35.3 & 34.7 & 41.8 & 28.4 & 35.1 \\
\hline \multicolumn{6}{|c|}{ Lesion size (mm) } \\
\hline Minimum & 6 & 6 & 4 & 6 & 4 \\
\hline Maximum & 52 & 35 & 45 & 35 & 53 \\
\hline Average & 17.53 & 16.01 & 14.65 & 16.63 & 16.21 \\
\hline \multicolumn{6}{|c|}{ Recurrence of lesion } \\
\hline Recurrence & $16(20.0 \%)$ & $24(27.9 \%)$ & 12(17.4\%) & $2(25.0 \%)$ & $54(22.2 \%)$ \\
\hline Non-recurrence & 64 & 62 & 57 & 6 & 189 \\
\hline
\end{tabular}

The nomenclature of FRGL is vast and complicated, with various terms used interchangeably to describe the various histopathological features of these $\mathrm{FRGL}^{9,10}$. This is best demonstrated where the terms calcifying fibroblastic granuloma, peripheral ossifying fibroma, peripheral cemento-ossifying fibroma, peripheral fibroma with calcification and ossifying fibrous epulis are used to describe the same entity in different studies ${ }^{11}$.

FRGLs are more common in females, which may highlight the influential role hormones may play in the pathogenesis of these lesions ${ }^{3,12,13}$. The binding of oestrogen to its receptor may stimulate connective tissue proliferation within the gingiva ${ }^{14}$. A predilection for the the anterior regions of the jaws (incisor-canine) compared with posterior areas (premolar-molar) has also been reported for FRGL ${ }^{15}$. The anterior region predilection may be partly explained by the tendency of supragingival calculus to occur predominantly in the anterior mandibular jaw ${ }^{16}$. The pooling of saliva in the anterior mandible provides a rich source of phosphate and calcium supersaturating the dental plaque resulting in calculus formation ${ }^{17}$. The cyclical periods of wetness and dryness in the anterior maxilla associated with mouth breathing has also been implicated in the predilection of FRGL in the anterior regions ${ }^{18}$.

The average diameter for a $\mathrm{LCH}, \mathrm{FFH}$ and POF is about 20 $\mathrm{mm}$, but the PGCG only averages $10 \mathrm{~mm}^{7}$. If not surgically resected early $\mathrm{LCH}$, POF and $\mathrm{FFH}$ can enlarge up to 40 $\mathrm{mm}$ in diameter causing difficulties with mastication and disfigurement? ${ }^{7,19}$. A PGCG rarely grows larger than $20 \mathrm{~mm}$, but lesions larger than $40 \mathrm{~mm}$ have been documented in patients with xerostomia ${ }^{7,19}$. The lack of the protective and cleansing action of saliva exacerbates the gingival irritation by calculus or plaque thus facilitating the growth of the $\mathrm{PGCG}^{19}$

The recurrence of FRGL following the use of conventional excisional techniques is quite common ${ }^{20}$. Incomplete gingival excision, persistent gingival irritation after excision and removal of lesions using a surgical blade have been reported to increase the risk of recurrence ${ }^{21}$. Deep excisions up to the involved periodontal ligaments, removal of chronic gingival irritants and resection by carbon dioxide lasers have been reported to reduce the recurrence rate ${ }^{20,21}$. Laser surgery is favoured because it promotes hemostasis and carbonisation of soft tissues which results in a precise clean resection ${ }^{22}$.

Other names that have been used to describe the $\mathrm{LCH}$ include granuloma pediculatum, pregnancy tumour, benign vascular tumour, vascular epulis and most commonly pyogenic granuloma ${ }^{4}$. The name pyogenic granuloma is misleading because no pus or pyogenic material is associated with the gingival mass ${ }^{10}$. Contamination of the granulation tissue by oral flora in a LCH can result in a fibrin exudate, which to the blind eye looks like pus ${ }^{4}$. Based on over 5200 cases of FRGL in India ${ }^{3}$, USA $^{23}$, Iran ${ }^{24}$ and China 25 the $\mathrm{LCH}$ comprises approximately $18 \%$ to $25 \%$ of all FRGL. This is in stark contrast with a study in Nigeria, where the $\mathrm{LCH}$ was the most common reactive lesion accounting for $57 \%$ of all cases $^{7}$. Studies from USA ${ }^{23}$, England ${ }^{26}$, Brazil $^{20}$ and India ${ }^{27}$ have reported that $\mathrm{LCH}$ has a maxillary jaw predilection. Though a study from Nigeria found no jaw predilection and one from China found a mandibular jaw predilection ${ }^{7,25}$

POF generally presents as a pink lesion, with some authors reporting only $36 \%$ of the lesions as red ${ }^{5}$. The general histopathologic pattern is primarily of a cellular connective tissue stroma associated with mineralised components $^{28,29}$. Dystrophic calcifications are more commonly seen in early growths whereas older lesions tend to have cementum or bone elements ${ }^{6}$. It is generally accepted that the POF has a maxillary jaw predilection ${ }^{25}$. Though a study in Nigeria reported that POF are equally distributed between the jaws and another study from India found all POF exclusively in the mandible ${ }^{7,30}$. The POF is generally a lesion of young females and teenagers with a peak incidence in the second and third decades of life ${ }^{6}$. In contrast, a study from China reported a higher average age of 44 years in patients with $\mathrm{POF}^{25}$.

$\mathrm{FFH}$ is also referred to as irritation fibroma, traumatic fibroma, fibrous epulis and fibrous nodule ${ }^{6}$. The lesion usually presents as a pink, nodular, non-ulcerated, painless gingival mass ${ }^{31}$. In studies of over 4800 reactive gingival lesions from USA ${ }^{23}$, China ${ }^{25}$ and Israel $^{31}$ it was reported that $\mathrm{FFH}$ was the most common reactive gingival lesion. Though a study in Nigeria found FFH 
TABLE II: Clinical variables

\begin{tabular}{|c|c|c|c|c|c|c|}
\hline Variable & $\mathrm{LCH}(n=80)$ & POF $(n=86)$ & FFH $(n=69)$ & PGCG $(n=8)$ & Total & $P$ value \\
\hline \multicolumn{7}{|c|}{ Anatomical distribution } \\
\hline Anterior maxilla & 37 & 39 & 30 & 2 & 108 & \multirow{4}{*}{0.978} \\
\hline Posterior maxilla & 11 & 8 & 8 & 1 & 28 & \\
\hline Anterior mandible & 22 & 29 & 21 & 3 & 75 & \\
\hline Posterior mandible & 10 & 10 & 10 & 2 & 32 & \\
\hline \multicolumn{7}{|l|}{ Pregnancy status } \\
\hline Pregnant & 15 & 8 & 4 & 0 & 27 & \multirow{2}{*}{0.044} \\
\hline Non-pregnant & 42 & 54 & 44 & 5 & 145 & \\
\hline \multicolumn{7}{|c|}{ Base of attachment } \\
\hline Pedunculated & 54 & 38 & 29 & 5 & 126 & \multirow[t]{2}{*}{0.005} \\
\hline Sessile & 26 & 48 & 40 & 3 & 117 & \\
\hline \multicolumn{7}{|l|}{ Colour of lesion } \\
\hline Erythematous & 67 & 43 & 34 & 2 & 146 & \multirow[t]{2}{*}{0.000002} \\
\hline Non-erythematous & 13 & 43 & 35 & 6 & 97 & \\
\hline
\end{tabular}

Table III: Correlation of size of FRGL and colour

\begin{tabular}{|l|c|c|c|}
\hline \multicolumn{3}{|c|}{ Table III: Correlation of size of FRGL and colour } \\
\hline Statistical test & $\begin{array}{c}\text { Colour of } \\
\text { lesion }\end{array}$ & P value \\
\hline Diameter & $\begin{array}{c}\text { Rank biserial } \\
\text { correlation }\end{array}$ & 0.175 & 0.006 \\
\hline
\end{tabular}

\section{Table IV: Correlation of size of FRGL and region of jaws}

\begin{tabular}{l|c|c} 
& Region of jaws (anterior/ posterior) & P value \\
Diameter & 0,126 & 0.05
\end{tabular}

to be the third most common reactive gingival lesion? Thus, geographical location and/ or ethnicity might play a large part in the relative frequencies of these lesions. Most studies in various countries have reported a female predilection for $\mathrm{FFH}^{3,23,25}$. In contrast a study from India reported a male predominance whilst another from Sweden reported no gender predilection ${ }^{30,32}$. There is no consensus on mean age for patients with $\mathrm{FFH}$ as it varies from 3rd to 5th decade of life ${ }^{7,31}$. FFH generally shows no jaw predilection ${ }^{23,7,31}$. However two studies from Sweden and China reported a mandibular jaw predilection ${ }^{25,32}$.

PGCG has been referred to as giant cell epulis and peripheral giant cell reparative granuloma ${ }^{6}$. PGCG usually presents as a purple to dark red gingival mass ${ }^{14}$. The extensive haemorrhage associated with the lesion will result in accumulation of hemosiderin that will impart the bluish hue ${ }^{2}$. PGCG was the least common reactive gingival lesion in most studies accounting for generally less than $11 \%$ of all lesions $7,23,25,31$. However, a study from Iran reported the PGCG as the most prevalent reactive gingival lesion ${ }^{24}$. The lesion is most common in the fourth decade of life and shows a mandibular jaw predilection ${ }^{31}$. On gender distribution, studies of PGCG have reported mixed results. While some studies reported no gender predilection ${ }^{23,33}$, others reported either a predilection for females ${ }^{32,34}$ or males ${ }^{24}$.

\section{AIM}

The aim and objectives of the study were to determine the relative frequency and distribution of FRGL according to sex, age, and anatomical site in patients who presented at the Witwatersrand Oral Health Centre.

\section{Methodology}

\section{Sampling method}

Utilising convenience sampling of patient records from the Department of Oral Pathology and the Department of Oral Medicine and Periodontology at the Witwatersrand Oral Health Centre, a retrospective cross-sectional study was performed. Past dental records from the years 2011 to 2017 were evaluated to select those with a histopathological diagnosis of FRGL.

\section{Inclusion and exclusion criteria}

Inclusion criteria were all patients who had dental records that contained at least $70 \%$ of the data required for the study ${ }^{35}$. The exclusion criteria for this study were (1) records of patients on anti-convulsant drugs, calcium channel blockers or the immunosuppressant cyclosporin, (2) cases diagnosed as epulis fissuratum, (3) reactive lesions presenting on sites other than the gingiva and (4) neoplastic conditions.

\section{Data collection and variables}

Histological and clinical history was obtained from the dental records. Sociodemographic variables (age, sex and occurrence of lesion during pregnancy) and clinical features (pedunculated/sessile lesion, size of lesion, colour, region of jaw affected) were recorded. Gingival lesions were anatomically classified into the following regions anterior (incisor-canine region) and posterior (premolar-molar region) according to the guidelines of Mergoni et al., 2015 36 . If the mass occupied both regions, it was grouped in the location where the bulk of the lesion was found ${ }^{36}$.

\section{Data analysis}

The relative frequency of histologically confirmed cases of FRGL was analysed by determining what percentage of the total number of histopathology cases analysed in the study was either LCH, POF, FFH or PGCG. For sex, base of attachment and anatomical sites, descriptive statistics were used. For the continuous variables such as age and size of lesions, the Shapiro-Wilk test was used to 
Figure 1. Frequency of FRGL and decade of life

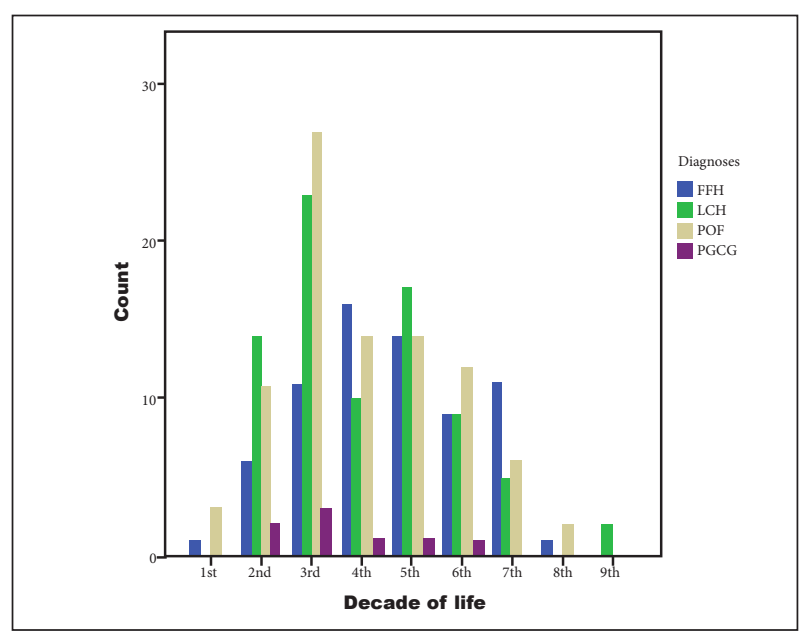

assess whether data followed a normal distribution. Crosstabulation analysis was used to summarise the categorical data. The chi-square test was used to assess statistically significant differences for categorical variables. Spearman rank correlation coefficient was applied to assess the correlation between age and size of FRGL. Rank biserial correlation coefficient $\left(R_{r b}\right)$ was used to analyse the correlation between, 1 size of FRGL and sex, and 2 size of FRGL and the jaw affected. The significance level alpha $(\alpha)$ was set at 0.05 for all statistical tests.

\section{Ethical considerations}

Ethical clearance was obtained from the Human Research Ethics Committee of the Faculty of Health Sciences at the University of the Witwatersrand (M180672).

\section{RESULTS}

A total of 243 cases of FRGL were evaluated and all were included in the study as per selection criteria. Female patients accounted for $70.8 \%(n=172)$ of all FRGL (Table I). The size of FRGL ranged from $4 \mathrm{~mm}$ to $52 \mathrm{~mm}$ in greatest diameter and the age of patients in this cohort ranged from 3 months to 88 years. The age did not follow a normal distribution (Shapiro-Wilk test $p>0.05$ ). The recurrence rates of FRGL were $22.2 \%(n=54)$ (Table I); with no statistically significant difference in recurrence rates between males and females.

A total of $56.0 \%$ ( $n=136$ ) of the lesions occurred on the maxilla. Of the 243 cases, $183(75.3 \%)$ were located anteriorly (incisor-canine region) and 60 (24.7\%) cases were located posteriorly (premolar-molar region) Table II. A total of $11.1 \%(n=27)$ of the lesions were associated with pregnancy, whilst pedunculated lesions accounted for $51.9 \%$ $(n=126)$ (Table II).

A total of $60.1 \%$ ( $n=146$ ) of all lesions were erythematous; and the correlation between the colour and the size of FRGL was statistically significant; $p$ value $=0.006$ (Table III).

The correlation of size of the FRGL and region of jaws affected (incisor-canine/ premolar-molar) yielded statistical significance; $\mathrm{p}$ value $=0.05$ (Table IV). The correlation between size of FRGL and age of patients was not statistically significant $(p=0.661)$. The frequency of the various FRGL and decade of life are shown in Figure 1. $L C H, P O F$ and PGCG were more frequent in the 3rd decade of life, whilst the FFH was more common in the 4th decade.

\section{DISCUSSION}

There is no consensus in the literature on which gingival variant is the most frequent FRGL; with most authors citing either the $\mathrm{LCH}$ or FFH $7^{23,31}$. In this study where 243 cases of FRGL, POF (35.4\%, $n=86$ ) was the most common, a feature not seen in any recent study utilising similar classification and methodology. The only comparative result found was by Macleod and Soames(1987) in England where POF constituted $40.5 \%$ of all gingival epulides ${ }^{26}$. The variation noted in this study may be partly accounted for by the differences in geographic and ethnic factors. Some authors argue that there is bound to be an overlap in histopathological diagnosis since FRGL represent a spectrum of one lesion, thus representing another possible source of the variation. Within a South African setting, this may be linked to challenges in accessing oral health care services, with resultant delayed diagnosis.

Studies in Chile ${ }^{16}$ and India ${ }^{37}$ contrary to our findings, found the POF to be the least common FRGL with a frequency of only $2.9 \%$ and $9.7 \%$ respectively. In most countries the frequency of POF, ranged from $10 \%$ to $25 \%$, representing the $2^{\text {nd }}$ or $3^{\text {rd }}$ most common FRGL ${ }^{7,23,25,31}$.

With a frequency of $32.9 \%$ the $\mathrm{LCH}$ was the second most common FRGL in this study. This agrees with most global studies that peg the frequency of $\mathrm{LCH}$ between $25 \%$ and $35 \%$ of all FRGL ${ }^{16,23,31,37}$. However contrary to our results, a study in Nigeria found the $\mathrm{LCH}$ to be the most frequent FRGL with a frequency of $57.0 \% \%^{7}$. The frequency of $\mathrm{FFH}$ across the globe is widely dispersed, ranging from $18.9 \%$ in $\operatorname{Iran}^{1}$ to $71.1 \%$ in Chile $^{16}$. The frequency of $\mathrm{FFH}$ in this study was $28.4 \%$ and is comparable to the $31.8 \%$ found in Israel ${ }^{31}$. PGCG was the least common FRGL in this study, a feature also seen in other studies ${ }^{2,716}$.

Numerous scholars have reported that FRGL have a predilection for females ${ }^{3,23,25}$, this study also found similar findings, with all four variants of FRGL occurring more commonly in females. Females accounted for $70.8 \%$ of all lesions which is comparable to $74.2 \%$ reported in Brazil ${ }^{2}$, and marginally more than the $62.7 \%$ reported in Nigeria ${ }^{7}$.

FRGL were significantly associated with pregnancy $(p=$ $0.044)$, with most cases linked to the LCH (55.6\% of all pregnancy cases diagnosed as LCH). This phenomenon was likely due to the vascular effects of female hormones on the gingiva ${ }^{2}$.

There was no statistically significant difference between frequency of FRGL in the maxilla and mandible. The frequency of FRGL in the maxilla was $56.4 \%$, slightly higher than the results seen in Israel (52.2\%) 31) and Nigeria (50.0\%) the PGCG had a higher frequency in the mandible (62.5\%), a trend which has also been seen in Nigeria 7, Israel 31 and Sweden ${ }^{32}$

Most lesions were located anteriorly incisor-canine region), as was observed in Brazil2. The pooling of saliva in this area favours calculus formation, which may result in gingivitis and most likely FRGL eventually. There was a statistically significant relationship between FRGL and colour ( $p=$ $0.000002)$. LCH was the lesion mostly associated with erythema, with $83.8 \%$ of all LCH presenting as erythematous, 
slightly higher than the $75.0 \%$ recorded in $\mathrm{Brazil}^{5}$ and $73.8 \%$ in Pakistan ${ }^{38}$. The bulk of the LCH lesion is angiomatous tissue formed from endothelial proliferation thus explaining the erythema ${ }^{6}$. In this study $50.0 \%$ of POF were shown to be erythematous, a finding which is higher than the 36.0\% and $33.4 \%$ recorded in Brazil $^{2}$ and Pakistan ${ }^{38}$ respectively. In this study $49.3 \%$ of FFH were erythematous which is comparable to the $55.1 \%$ reported in Pakistan ${ }^{38}$. Only 25\% of the PGCG in this study were erythematous this might be due to the variation in the amount of hemosiderin or extravasated blood in various PGCG lesions which results in a wide spectrum of colours at presentation that include red, bluish, pink and pale pink ${ }^{3}$.

In this study $74.9 \%$ ( $n=182$ ) of all FRGL were greater than $10 \mathrm{~mm}$, similar findings were also reported in Pakistan ${ }^{38}$ The FRGL ranged from $4 \mathrm{~mm}$ to $52 \mathrm{~mm}$, mirroring findings in Nigeria ${ }^{7}$. Like the study in Nigeria ${ }^{7}$, the average size of the LCH was found to be the largest of all FRGL. There was a low but statistically significant correlation between the size of FRGL and the colour of the lesions (Rank biserial correlation $=0.175$ ), with erythematous lesions being generally larger. Low statistically significant relationships were also found between the size of FRGL and location of lesion (anterior/posterior, Rank biserial correlation = 0.126). Lesions tended to be larger in the posterior region, and this could be partly explained by the fact that patients are more likely to seek treatment earlier for anterior lesions because of a higher aesthetic demand. There was no statistically significant correlation between size of FRGL and age of patients ( $p=0.661$ ), with the largest lesion occurring in a 19-year-old female patient.

The youngest patient in the study was 3 months old and was diagnosed with a POF. The baby was healthy and was born with anterior mandibular teeth that later exfoliated. Similar cases have been reported in literature, with the authors assuming the irritation in the periodontal ligament that results from exfoliation may trigger gingival connective tissue metaplasia with resultant dystrophic calcifications ${ }^{39}$. POF, LCH and PGCG occurred more frequently in the 3rd decade of life, with similar results being reported in Nigeria $^{7}$ and Israel ${ }^{31}$. FFH was more common in the $4^{\text {th }}$ decade, a feature also noted in Israel ${ }^{31}$, though a study in Nigeria ${ }^{7}$ and Chile ${ }^{16}$ found lesions more common in the $3^{\text {rd }}$ and $6^{\text {th }}$ decade respectively.

The mean age of patients with POF was 34.7 years, which is comparable to 33.9 years reported in Israel $\left.\right|^{31}$ and 31.5 years reported in the USA ${ }^{23}$. Though mean age for POF was noted to be way higher in China at 44.2 years ${ }^{25}$. The mean age for a LCH was 35.3 years, with similar mean ages being reported in the USA ${ }^{23}$ and China ${ }^{25}$. The lower mean age for POF compared to $\mathrm{LCH}$ does not corroborate the progressive development theory, that postulates that a POF evolves from of $\mathrm{LCH}$ via further collagenisation and mineralisation ${ }^{8}$. Thus, this brings into question whether the $\mathrm{LCH}$ and POF are the same lesion at various histopathological developmental stages.

There was no statistically significant difference in the recurrence rates of FRGL in this study. The recurrence rate of $22.2 \%$ recorded in this study is higher than the $2.9 \%$ reported in Nigeria?. The POF and FFH had the highest and lowest recurrence rates respectively, a feature also reported in India ${ }^{21}$. There was also no statistically significant difference in recurrence rates between males and females, hence female hormones may not be key to recurrence rates.

\section{Limitations of study}

The study fell victim to a major hurdle of retrospective studies, that is, all information gathered is solely dependent on the available information in the dental records. Unfortunately, this resulted in insufficient data being gathered on race, plaque index, DMF index, nature of chronic irritation and presence of ulceration. Pregnancy status evaluation was solely based on information gathered on the dental chart, thus some early unknown pregnancies may have gone undetected. Since FRGL in dental charts were mostly classified either as erythematous or nonerythematous rather than specify the true colour of the lesion this might have been a source of error.

\section{CONCLUSION}

As in most studies the FRGL were more common in females in this study. Contrary to results of similar studies done in other countries, POF was the most common variant of FRGL after analysing 243 cases in this study. Statistical differences for FRGL were noted on pregnancy, base of attachment (sessile and pedunculated) and colour of lesions. An understanding of the clinical picture may aid in the diagnosis of FRGL, but histopathological evaluation is still required for a definitive diagnosis.

Retrospective studies are heavily dependent on data available in patient records. Given the amount of missing data encountered in the study, we recommend detailed and accurate documentation of findings by clinicians in order to facilitate future research. Based on our findings that do not corroborate the progressive development theory of POF from $\mathrm{LCH}$, we recommend more studies on the histopathogenesis of FRGLs.

\section{Conflict of Interest}

No conflict of Interest. Research was self-funded.

\section{References}

1. Zarei MR, Chamani G, Amanpoor S. Reactive hyperplasia of the oral cavity in Kerman province, Iran: A review of 172 cases. Br J Oral Maxillofac Surg. 2007;45(4):288-92.

2. Dutra KL, Longo L, Grando LJ, Rivero ERC. Incidence of reactive hyperplastic lesions in the oral cavity: a 10 year retrospective study in Santa Catarina, Brazil. Braz J Otorhinolaryngol. 2019;85(4):399-407.

3. Reddy V, Saxena S, Saxena S, Reddy M. Reactive hyperplastic lesions of the oral cavity: A ten year observational study on North Indian population. J Clin Exp Dent. 2012;4(3):136-40.

4. Kamal R, Dahiya P, Puri A. Oral pyogenic granuloma: Various concepts of etiopathogenesis. J Oral Maxillofac Pathol. 2012;16(1):79-82.

5. Peralles PG, Viana APB, Azevedo AL da R, Pires FR. Gingival and alveolar hyperplastic reactive lesions: clinicopathological study of 90 cases. Braz j oral sci. 2006;5(18):1085-9.

6. Neville BW, Damm DD, Allen CM, Chi A. Oral and maxillofacial pathology. 4th ed. Philadelphia: W.B. Saunders; 2002. 473-526.

7. Effiom OA, Adeyemo WL, Soyele OO. Focal Reactive lesions of the Gingiva: An Analysis of 314 cases at a tertiary Health Institution in Nigeria. Niger Med J. 2011;52(1):35-40.

8. Prasad S, Reddy SB, Patil SR, Kalburgi NB, Puranik RS. 
Peripheral ossifying fibroma and pyogenic granuloma. Are they interrelated? N Y State Dent J. 2008;74(2):50-2.

9. Kumar SKS, Ram S, Jorgensen MG, Shuler CF, Sedghizadeh PP. Multicentric peripheral ossifying fibroma. J Oral Sci. 2006;48(4):239-43.

10. Rossmann JA. Reactive Lesions of the Gingiva: Diagnosis and Treatment Options. Open Pathol J. 2011;5(1):23-32.

11. Buchner A, Hansen LS. The histomorphologic spectrum of peripheral ossifying fibroma. Oral Surgery, Oral Med Oral Pathol. 1987;63(4):452-61.

12. Kenney JN, Kaugars GE, Abbey LM. Comparison between the peripheral ossifying fibroma and peripheral odontogenic fibroma. J Oral Maxillofac Surg. 1989;47(4):378-82.

13. Miller CS, Henry RG, Damm DD. Proliferative Mass Found in the Gingiva. J Am Dent Assoc. 1990;121(4):559-60.

14. Günhan M, Günhan Ö, Celasun B, Mutlu M, Bostanci H. Estrogen and progesterone receptors in the peripheral giant cell granulomas of the oral cavity. J Oral Sci. 1998;40(2):57-60.

15. Tamiolakis P, Chatzopoulou E, Frakouli F, Tosios KI, SklavounouAndrikopoulou A. Localized gingival enlargements. A clinicopathological study of 1187 cases. Med Oral Patol Oral y Cir Bucal. 2018;23(3):320-5.

16. Maturana-Ramírez A, Adorno-Farías D, Reyes-Rojas M, Farías-Vergara M, Aitken-Saavedra J. A retrospective analysis of reactive hyperplastic lesions of the oral cavity: study of 1149 cases diagnosed between 2000 and 2011, Chile. Acta Odontol Latinoam. 2015;28(2):103-7.

17. Dawes $C$. Why does supragingival calculus form preferentially on the lingual surface of the 6 lower anterior teeth?. J Can Dent Assoc. 2006,72(10):923-6.

18. Agrawal AA. Gingival enlargements: Differential diagnosis and review of literature. World J Clin Cases. 2015;3(9):779-88.

19. Bodner L, Dayan D. Growth potential of peripheral ossifying fibroma. J Clin Periodontol. 1987;14(9):551-4.

20. Salum FG, Yurgel LS, Cherubini K, De Figueiredo MAZ, Medeiros IC, Nicola FS. Pyogenic granuloma, peripheral giant cell granuloma and peripheral ossifying fibroma: retrospective analysis of 138 cases. Minerva Stomatol. 2008;57(5):227-32.

21. Babu B, Hallikeri K. Reactive lesions of oral cavity: A retrospective study of 659 cases. J Indian Soc Periodontol. 2017;21(4):258-63.

22. Pearson GJ, Schuckert $\mathrm{KH}$. The role of lasers in dentistry: present and future. Dent Update. 2003;30(2):70-4

23. Kfir $\mathrm{Y}$, Buchner A, Hansen LS. Reactive lesions of the gingiva. A clinicopathological study of 741 cases. J Periodontol. 1980;51(1):655-61.

24. Naderi NJ, Eshghyar N, Esfehanian $\mathrm{H}$. Reactive lesions of the oral cavity: A retrospective study on 2068 cases. Dent Res J (Isfahan). 2012;9(3):251-5.

25. Zhang W, Chen Y, An Z, Geng N. Reactive gingival lesions: A retrospective study of 2,439 cases. Quintessence Int (Berl). 2007;38(1):103-10.

26. Macleod RI, Soames J V. Epulides: A clinicopathological study of a series of 200 consecutive lesions. Br Dent J. 1987;163(2):51-3.

27. Shamim T, Varghese V, Shameena P, Sudhas S. A retrospective analysis of gingival biopsied lesions in south indian population. Med Oral Patol Oral y Cir Bucal. 2008;13(1):441-8.

28. Mishra MB, Bhishen KA, Mishra S. Peripheral ossifying fibroma. J Oral Maxillofac Pathol. 2011;15(1):65-8.

29. Shetty D, Urs A, Ahuja P, Sahu A, Manchanda A, Sirohi Y. Mineralized components and their interpretation in the histogenesis of peripheral ossifying fibroma. Indian $J$ Dent Res. 2011;22(1):56-61.

30. Kashyap B, Reddy Ps, Nalini P. Reactive lesions of oral cavity: A survey of 100 cases in Eluru, West Godavari district. Contemp Clin Dent. 2012;3(3):294-7.

31. Buchner A, Shnaiderman-Shapiro A, Vered M. Relative frequency of localized reactive hyperplastic lesions of the gingiva: a retrospective study of 1675 cases from Israel. J Oral Pathol Med. 2010;39(8):631-8.

32. Anneroth G, Sigurdson A. Hyperplastic lesions of the gingiva and alveolar mucosa: A study of 175 cases. Acta Odontol Scand. 1983;41(2):75-86.
33. Daley TD, Nartey NO, Wysocki GP. Pregnancy tumor: An analysis. Oral Surgery, Oral Med Oral Pathol. 1991;72(2):196-9.

34. Eversole LR, Rovin S. Reactive lesions of the gingiva. J Oral Pathol. 1972;1(1):30-8.

35. Oliveira ML aur. C, Wagner VP eterse., Sant'ana Filho M, Carrard VC oelh., Hugo FN eve., Martins MD omingue. A 10-year analysis of the oral squamous cell carcinoma profile in patients from public health centers in Uruguay. Braz Oral Res. 2015;29(1):1-8.

36. Mergoni G, Meleti M, Magnolo S, Giovannacci I, Corcione L, Vescovi P. Peripheral ossifying fibroma: A clinicopathologic study of 27 cases and review of the literature with emphasis on histomorphologic features. J Indian Soc Periodontol. 2015;19(1):83-7.

37. Patil S, Somashekar S, Wadhawan R, Deoghare A, Khandelwal $S$, Maheshwari S. Prevalence of reactive hyperplastic lesions of the gingiva in the Western Indian population. J Orofac Sci. 2014;6(1):41.

38. Kazmi F, Alamgir W, Mumtaz M. Diagnostic Challenges in assesement of reactive soft tissue lesions of oral cavity. Int $\mathrm{J}$ Cur Res Rev. 2015;7(10):79-86.

39. Kohli K, Christian A, Howell R. Peripheral ossifying fibroma associated with a neonatal tooth: case report. Pediatr Dent. 1998;20(7):428-9. 